\title{
Smart Interactive Buildings [SIBs]: The use of Ambient Intelligent Systems [AMIS] to Enable Smart Interactive Settlements [SISs] Mahmoud Al Saeed ${ }^{1}$; Fodil Fadli² \\ ${ }^{1,2}$ Department of Architecture and Urban Planning, College of Engineering, Qatar University, Qatar \\ f.fadli@qu.edu.qa
}

\section{Abstract}

The $21^{\text {st }}$ Century is witnessing the dawn of Industry [I4.0], or the fourth Industrial Revolution. With burgeoning technological inventions linked to smart interactive cities and intelligent buildings, where humans-machines-spaces interact continuously.

Our ambition in this explorative study is to design and develop a sophisticated interactive computational platform that interacts and responds to humans' [users] needs and aspirations, which are increasing exponentially, in complete synchronization with machines, spaces and buildings' capacities. Consequently, there is a demand and necessity to develop Ambient Intelligent Systems (AMIS) which enable the creation of intelligent settlements that efficiently ease the communication between users/ users, users/machines and users/buildings. This is importantly needed in order to reduce the ascending consumption rate of energy in an integrative design manner.

The aim of this study is to investigate the current technological solutions that address the subject of human/buildings [includes machines and spaces] interaction through sensory devices and computational systems. This can be achieved through the design and development of a comprehensive understanding of the human/buildings interactions, in the form of Ambient Intelligent Systems that enable the interaction of different stakeholders and users with the building they live/work in, at realtime. This will solve any problem related to energy usage and hence environmental quality control indoor-outdoor of the building.

The findings of this study demonstrate the necessity of integrating AMIS solutions into the early stages of buildings design as a primary method of Design, Build and Operation (DBO). Earlier computational design technologies would help develop an Advanced Design, Analysis and Management System (ADAMS). This system has been simulated and validated effectively to enable human-buildings constant interactivity at all time in real-time reaction. AMIS solutions through ADAMS model lead us as designers, architects, planners and users to consider our buildings as an interactive living entity rather than a static conventional mass. Humans-Buildings-Spaces interaction through AMIS platforms will be capable of collecting, analyzing, synthesizing and developing adequate customized decisions at their own, as Artificially Intelligent [AI] constituents of the Smart Interactive Buildings [SIBs] network, which would undoubtedly lead to reduced energy consumption and healthier livable Smart Interactive Settlements [SISs].

Keywords: Ambient Intelligent Systems [AMIS]; Smart Interactive Settlements [SISs]; Smart Interactive Buildings [SIBs].

\section{Introduction}

Today cities obtain a great power to attract population, this power presented in the variety of economic opportunities and amenities has driven more than $50 \%$ of world population to live in urbanized settlements where this shift expected to reach $60 \%$ in 2030. Although urbanized areas provide better 
live opportunities, yet side effects come along with population shift such as depletion of the natural resource mainly water, energy, and increased greenhouses emissions leading to damage of the natural environment and decreased inhabitant quality of life.

According to the International Energy Agency (IEA), the total energy consumed in 2003 has reached more than 106,996 TWh/y (annual consumption of energy estimated by terawatt per hour), which augmented in 2016 to $125,500 \mathrm{TWh} / \mathrm{y}$, simultaneously our cities consume 4 trillion cubic meters of energy per year, where the buildings sector alone is accounted for $35 \%$ of total energy consumption and $26 \%$ of the total water consumed (IEA, 2016). At the same time today technology has become more sophisticated, intelligent and objective, the applications of "smart" technology plays an important role in the process of Design Built and Operation (DBO) of our buildings, neighborhoods and cities, where the use of "intelligent" computational technology has proven its capacity to reduce the energy and water consumption in buildings up to $30-80 \%$ (based on the level of technology integration) (Fadli \& Saeed, 2018).

With that in mind, the conventional concepts of cities as the total of built and open spaces with its supporting infrastructure, is no longer enough to define cities and solve their emerged issues. Thus, the use and integration of Ambient Intelligent Systems (AMIS) with building design, operation and management method is the future of building and energy management systems that increase the interaction between users and their environment to reach the goals of sustainable design and enhance the quality of life.

The aim of this study is to investigate current technological solutions that address the increasing demand of energy and water, along with human-buildings interaction and relationships, to develop comprehensive solutions that uses the Ambient Intelligent System [AIMs] as intelligent management platforms. This will solve any problem related to energy usage and hence environmental quality control indoor-outdoor of the building.

In order to achieve this, the authors of this study have conducted thorough critical analysis of the existing literature related to the subject of water and energy management systems with its delivery structures, along with the subjects of smart cities, like the concepts of the Internet of Things [IoT] and, Building Information Modeling (BIM), where the analysis of the previous study paves the way to construct a systemic intelligent management and monitoring platform, that opens the doors for further development in water-energy management systems. Ideally, to the resolution of the issues of resource bleeding and human- building interaction.

The findings of this study demonstrate the importance of integrating computational technology solutions into the processes of building Design, Built and, Operation (DBO), to address the existing issues and those predicted of the increasing demand on energy and water along with the issue of building and user's interaction. The findings of this study form the foundation of the Advanced Design, Analysis and Management System (ADAMS) as fully integrated, with intelligent management and operation platform, hence leading to the resolution of investigating issues of water, energy and, management systems (Fadli \& Saeed, 2019; Boguslawski et al., 2015).

\section{Conceptual Framework}

Beyond doubt, the issues of increasing consumption rate of energy and water are rising every year with no clear systemic method or solutions leading to decrease in the quality of life and increase in the natural environment threats and challenges.

The conceptual framework of this study works on integrating theories of practice with actual practice techniques to create an intelligent tool (Advanced Design, Analysis and Management System - 
platform) that is efficient and reliable to carry out designs, simulations, and calculate the accurate needs of energy and water, Moreover to predict the possible issues, along with a simple yet intelligent and effective management tool - that increases the interaction between users and buildings.

In that sense the authors have divided this study into three phases, starting by identifying the core concepts of the subjects of Smart Interactive Building (SIB's), water and energy management system, Ambient Intelligent Systems Applications as well, where the finding has been merged together to formulate a group of recommendations and create the Advanced Design, Analysis and Management

\section{Smart Interactive Buildings [SIBs]}

Phase 1

Phase 2

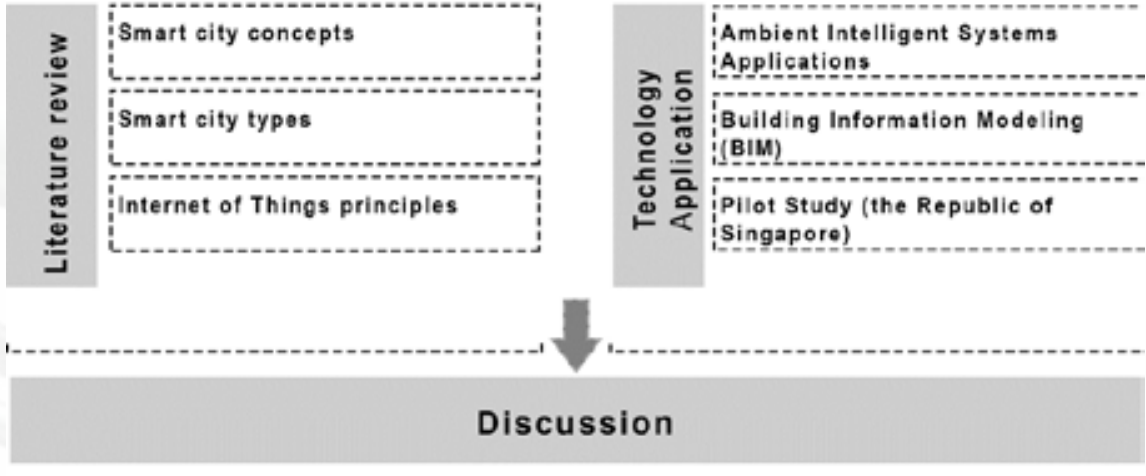

Advanced Design, Analysis and Management System (ADAMS)

Figure 01: Schematic development diagram of the conceptual framework.

\section{Background Developments}

This section investigates existing knowledge of the subject of smart cities, and technology applications in the process of building, energy and water management systems. Moreover, a pilot study was conducted to explore and highlight over what the current attempt has done to the resolution of the identified issues.

\subsection{The "Smart City" Concept}

The city that has the ability to collect, analyze and react towards information in a spatial context is considered as a "smart city". Although the concept of smart cities is relatively new, yet it succeeds to attract more attention among scholars and practitioners. The definition of smart city includes the aspects of several engineering fields such as communication technology, infrastructure planning, urban planning, and environmental design along with none engineering fields like economic, social and management methods. In that sense the smart city is the interaction and integration between environment and users through the physical infrastructure such as sensory systems and interaction system, at the same time, it's a communication method between objects and people (Harrison et al., 2010).

Scholars have identified several types of smart cities based on the method of the level of operation and interaction, where the most common types are the cities that depend and intensively use the applications of technology. Figure 2 lists and identifies the most common types of smart cities and their method of operation (Cocchia, 2014). 


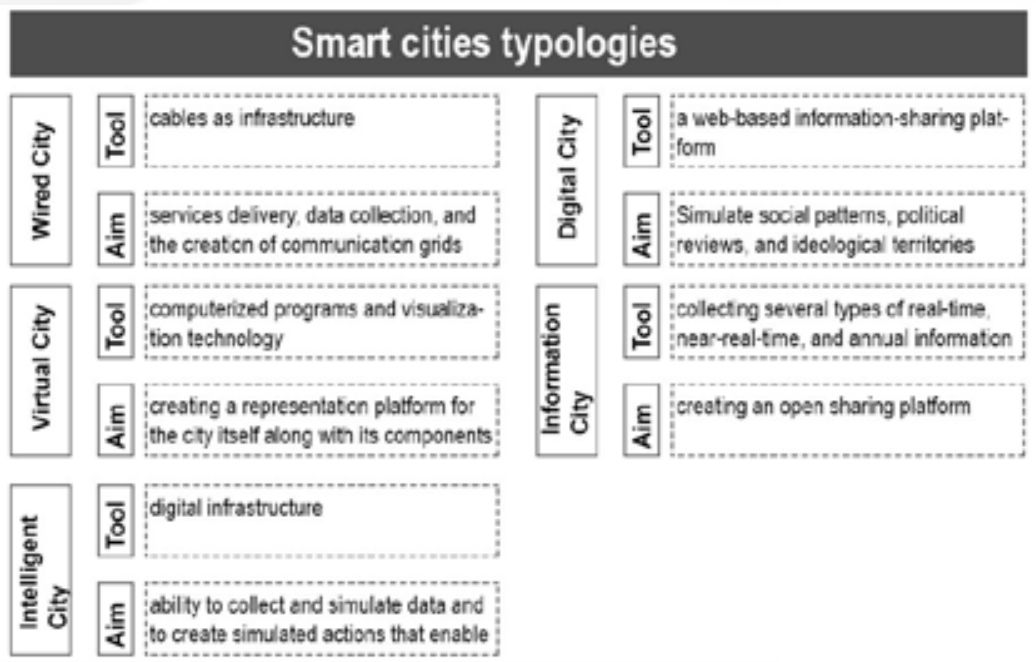

Figure 2: Smart city typologies deciphering (Saeed \& Fadli, 2018 adapted from Cocchia, 2014).

The process of creating smart cities requires a deep integration between the physical (users and buildings) and none physical components (technology and programs) to establish intelligent and interactive techniques with integrated capacity to design, simulate and analyze the information generated from the city components and users (Figure 3).

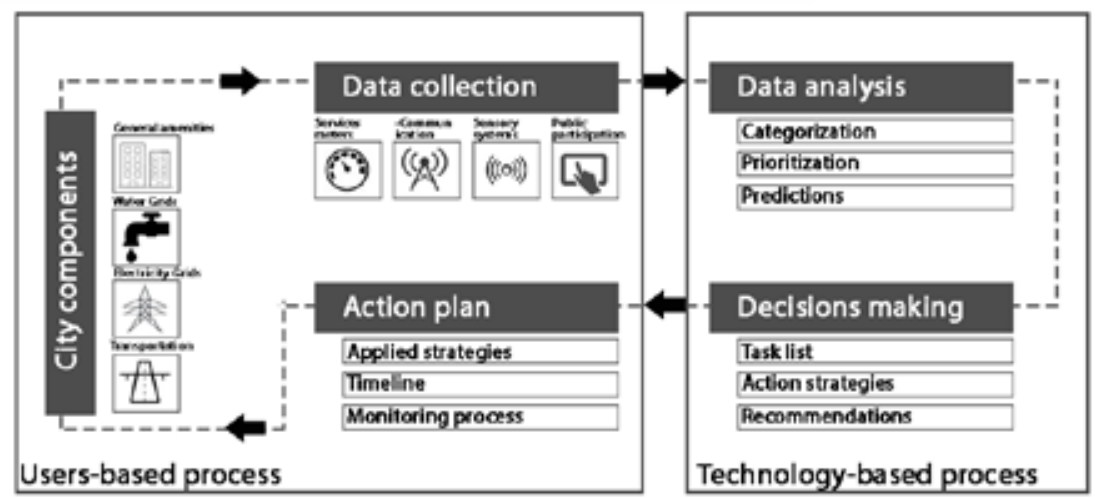

Figure 3: Smart city operational framework (Saeed \& Fadli, 2018).

\subsection{Internet of Things: Principles and Applications}

Generally speaking, Internet of Things (IoT) concept describes the uses and applications of smart devices as multitasking tools that obtain a great capacity to communicate, collect and transfer several types of raw information's such as (weather conditions, geographical locations, consumption behaviors and, social patterns) to dedicated sharing platform (as human- buildings interactions platforms), and works as secondary information collectors as well.

The benefits of adapting IoT concepts comes from the possibility to track and record the information's in real-time with spatial context labeling and allowing the ambient intelligent systems (such as a computerized program) to categorize and analyze data, generating actual and predicting scenarios that support decision making and promote real-time interaction. Figure 4 below describes the type of interaction and the IoT method of operation. (Dohr et al., 2010; Zanella et al., 2014). 


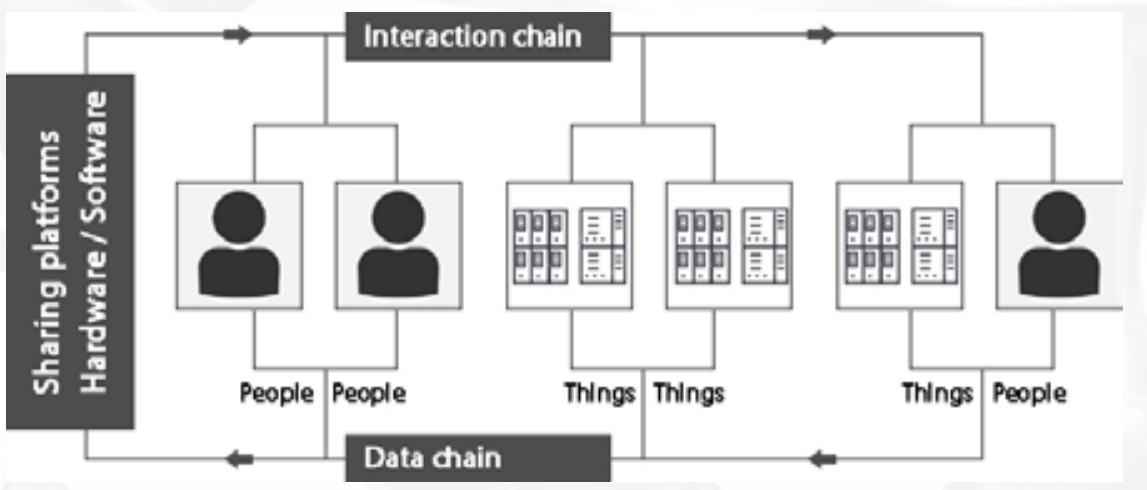

Figure 4: Internet of Things (IoT) systemic applications.

Adapting the concepts and method of IoT is vital to create smart cities, where integration of multitasking smart devices used as daily life tools forms the efficient and sustainable way instead of planting and integrating dedicated sensory systems where using this type of devices is extremely expensive and considered as an unnecessary cost.

\subsection{Ambient Intelligent Systems Applications}

Generating designs by the conventional methods requires a considerable amount of effort and costs, at the same time the conventional methods of designs miss the opportunity to predict the issues that might occur during the construction. Meanwhile, today technology (computer programs) is much more than mathematical equations and operation matrix, where today computational programs obtain a great level of intelligence to simulate and generate future scenarios and even propose different methods to face such challenges (Fadli et al., 2015; AlSaaed, 2018).

The current computer programs for design and monitoring can be easily classified into three main classes (Figure 5) based on the type of use and level of complexity, where it starts by the individual building to the group of building and finally to the scale of cities (AlSaaed, 2018).

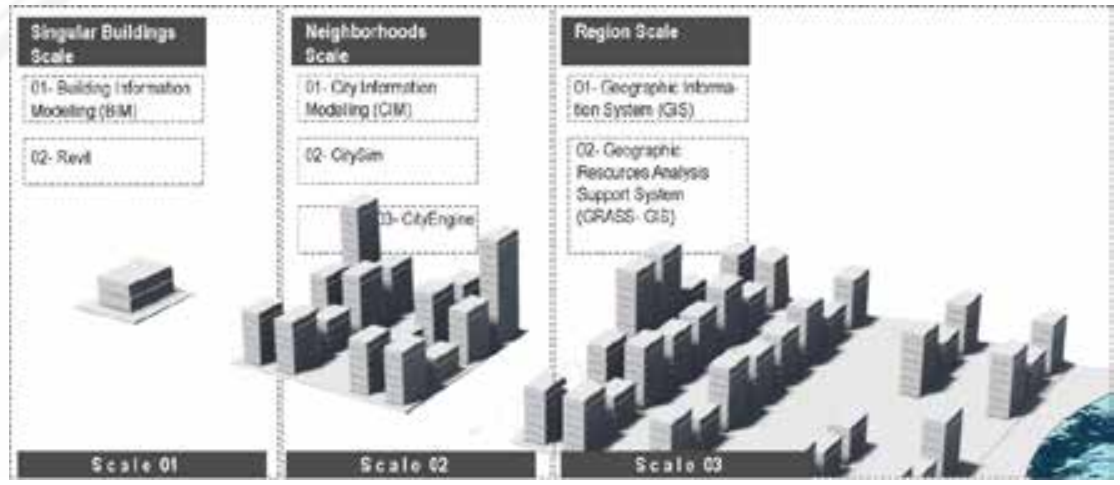

Figure 5: Program classification (Fadli \& Saeed, 2018).

Building Information Modeling (BIM): is one of the direct applicators of AMIS. BIM is a computerized program that uses technology and simulation tools for design, construction, and facility management, aiming to translate the 2D information's into three-dimensional interactive platform by overlapping all design data together. The program defines the construction into three main categories that includes (Eastman et al., 2011) (Figure 6):

- Construction components: which in total forms the spaces and finally the buildings itself.

- Design data: it's the information that forms the design which in general describes the building method of operation and users' behaviors 
- Coordination data: it is the collaboration between building component with buildings system and the data generated from monitoring the building systems' functions.

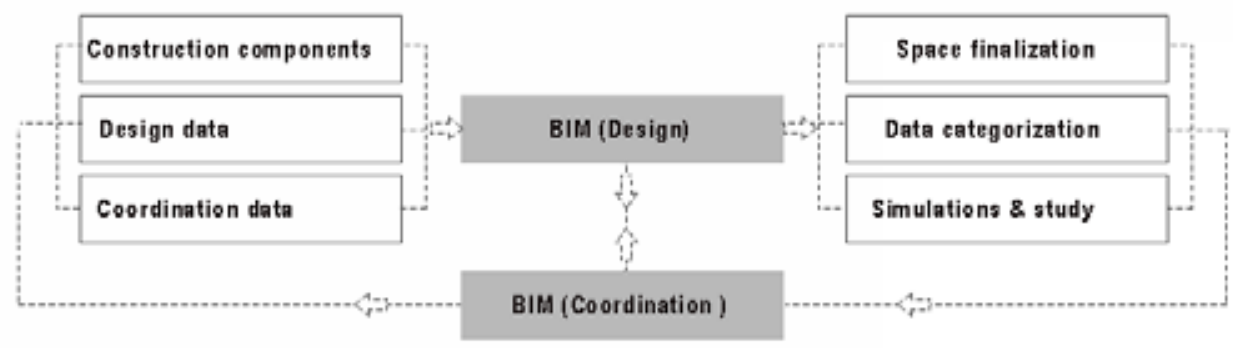

Figure 6: BIM operation method.

\section{Case Study (the Republic of Singapore)}

Described as one of the densest populated islands in the world, Singapore has a population of 5.5 million, allocated on $597 \mathrm{~km}^{2}$ (Figure 7), where the population is composed of different races such as Chinese, Malays, Indians, and Eurasians as well (SDS, 2014). Its geographical location near to equator gives it a consistent hot and humid weather. The island of Singapore has very limited resource, where it has no energy deposits, no large forest, and even the agricultural land is very limited (CfC , 2015) despite all the geographical challenges, Singapore has grown to one of the most advanced countries in the world. The economy is fully dependent on financial service, oil revenues and manufacturing.
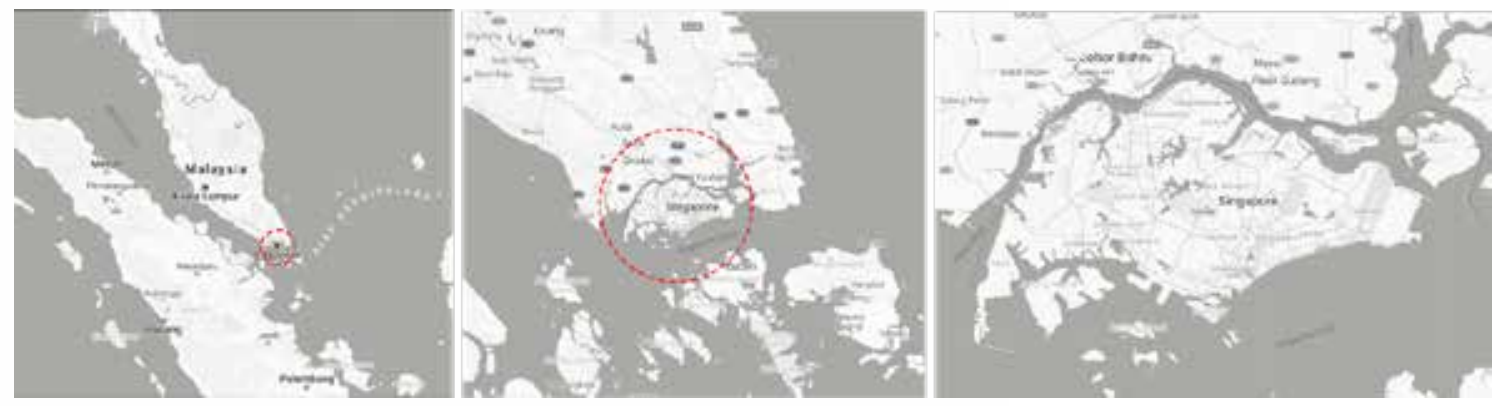

Figure 7: City of Singapore, Republic of Singapore (Fadli \& Saeed, 2018)

Responding to the growing challenges of population boom, environmental degradation and resource bleeding (mainly energy and water); the Singapore Government took action. This consisted of Singapore Government Smart Nation (SGSN) vision that seeks to integrate the modern concepts of communication technology, information technology, and data collection strategies in order to develop the nation 'living lab' initiative that supports the human quality of life and open new field for smart solutions implementation (Ke \& Wei, 2004; Komninos, 2009).

\subsection{Systems Configuration}

Singapore's experience of transferring the infrastructure to fully intelligent services, was developed at stages, where the huge amount of data collected is distributed on several databases, control centers and intelligent applications, with the aim to integrate all government agencies together, and bring the inhabitant closer to the services provided by government as well, the configuration of various systems includes the following process (Keon et al., 2016): 
01- Physical systems integration: Integrating the urban sector (urban mobility, logistic and environment), industry sector (manufacturing and manpower), and smart platforms (operating systems and communication network and sensory infrastructure) all together to work continually with each other, the heart of the physical integration is operated and monitored through (Leonard, 2014; Intermediary, 2014):

- Sensor management: where both video and non-video sensors collect the data and send it to the filed facilities, to be classified and monitored according to their function and type a constancy and real time assessment method applies according to the data type (information, activation, configuration data, and so on).

- Data exchange: the collected, and classified information distributed into a unified sharing platform that is available and secure all the time, a group of security policies and open standards protocols apply to make sure the important data is safe and open for all government agencies and users together.

- Sense-making platform: the purpose of the integrated platforms is to process the data that is relevant to requested information, in other words the sensing platforms are the core of the intelligent process that give life to the user interface technology.

02- Control centers integration: the distributed command centers in the city of Singapore work in parallel at two different layers, where each command center is operated by its responsible agency like the transportation command center is run and maintained by the transportation authority, therefore there is no threat of major failure, meanwhile all the centers report to main control and management database making the information sharing available at real-time and accessed in any command center (Keon et al. 2016). The reason to create several operating centers is to cut the cost of operation, where some of the services require 24/7 through the year monitoring (such as security, citizen public health and so on) and other centers require annual inspections and checkup only.

03- Operative systems integration: the operative systems are the tools to collect and store the information where it has a secure connection to command centers, and where all the readings and information are stored classified and analyzed, the operative systems or the filed sensing systems includes (Keon et al., 2016; Urban Environmental Management, 2015; Kiat, 2016).

\section{Discussions and findings}

The conventional methods of urban planning maintained its rigid form for long time, although its principles are important and reliable, but it is not sufficient in keeping up with the challenges of current century and need emerged by environmental, social, and cultural changes. Hence, the necessity of harvesting the benefit of technology is increasing and today planning authorities must act in order to achieve a better understanding and adoption of technology and intelligent planning methods specifically artificial intelligence powered by man-machine interaction. The noticeable improvement of [AI] software's have proven their capacity and important role to support and enhance the process of design, leading to effective responsible and reliable designs. Yet the limitation of coordination is obvious and can't be overlooked, where almost all of design software's work at individual level and mismatching and coordination between the results almost absent.

Planning vision for future cities and enhancing existing cities needs to meet smart city requirements and methods of operation, where it should be included from the early stages of planning and design. Designs and planning is a multi-stage action, therefore technology and computerized applications shall respond to the needs of designers and planners, at the same time there are increasing demands on providing smart softwares that understand the planning process and characteristics and respond to real-time design variables. 
The increasing demand on the resources (energy and water) can't be overlooked, in parallel intelligent softwares have significantly developed with a great capacity to collect, simulate and analyze data, hence planning authorities must adopt a real-time analysis and simulation programs to allocate and predict the issues before it occurs, and channel the correct amount of resources where it is required..

\section{Advanced Design, Analysis and Management System (ADAMS)}

By revisiting the reviewed works of literature on this research along with the discussion built, the aim is to shape and create a tool (that possesses several abilities) to build a bridge between theoretical discussions of urban planning, design, smart city concepts, and technology applications, the creation of a comprehensive software with the ability of self-operating, monitoring which is interactive, with its users, not only as operation software but as a design application as well.

The proposed application; Advanced Design, Analysis \& Management System (ADAMS) has been built into three main functions that include design process, institutional operation, and resource management, each function having several aims and sub-abilities (Figure 8), where all the functions are merged together by using web sharing platforms (clouded platforms).

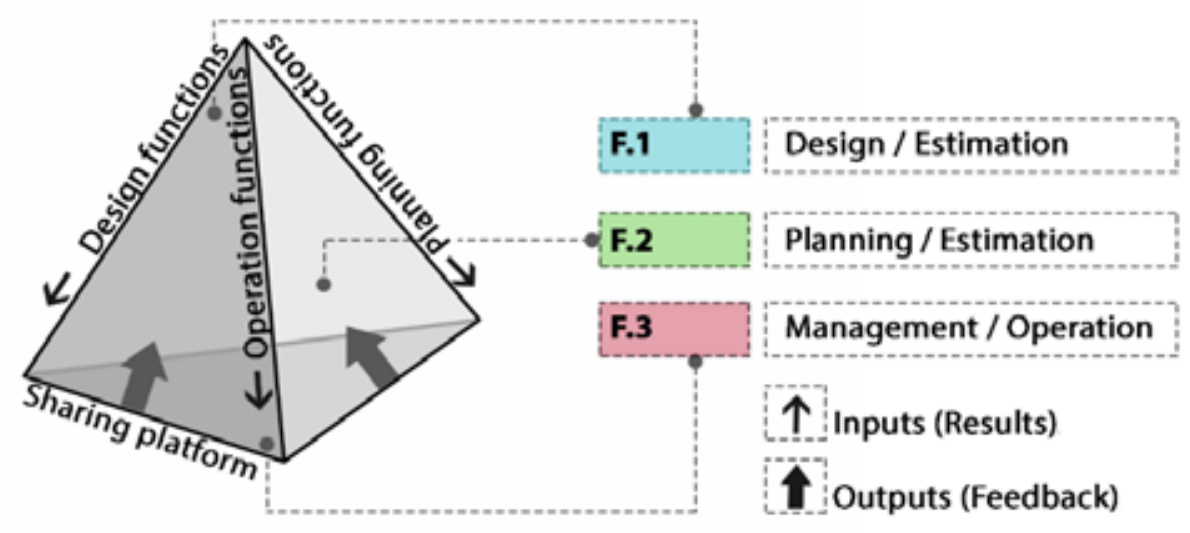

Figure 8: ADAMS main functions (source: Authors, 2018)

ADAMS' proposed method of operation works simultaneously to coordinate the outputs between designer, users, and authorities. This coordination process aims to generate responsible designs with high ability of coordination prior and after construction, the general method of operation is based on the main function provided by ADAMS as follows (see Figures 9 and 10):

- Design function: used by individuals and consultancy firms to prepare architectural drawings, electrical designs and mechanical systems, based on interactive programs method. The added values of ADAMS is the possibility to generate simulation and analysis that is compared and matched with local standards and regulation to foster the approvals and construction process, saving time and cost, ensuring that designs are accurate that provides actual need of the building eliminating the waste in energy and water consumption by using the simulation and prediction technology.

- Authorities function: dedicated to planning institutions and governmental agencies that are in charge of planning, providing and managing the infrastructure such as water and electricity, the main purpose of this function is to generate overall consumption standards and in its focused capacity provide specific regulation and standard for each plot. At the same time the ability of this tool includes integration into built city fabric at the individual level (buildings scale), to monitor in real-time the consumption and behavior readings, which analyzed and transferred into action to prevent unwanted resource consumption. 
- Operation \& Management function: the wide adaption of Building Management System (BMS), which can be described as the building brain. ADAMS works on integrating the individual BMS's into one platform under authority monitoring to notification building users about their consumption rate and behaviors of consumption in real-time.

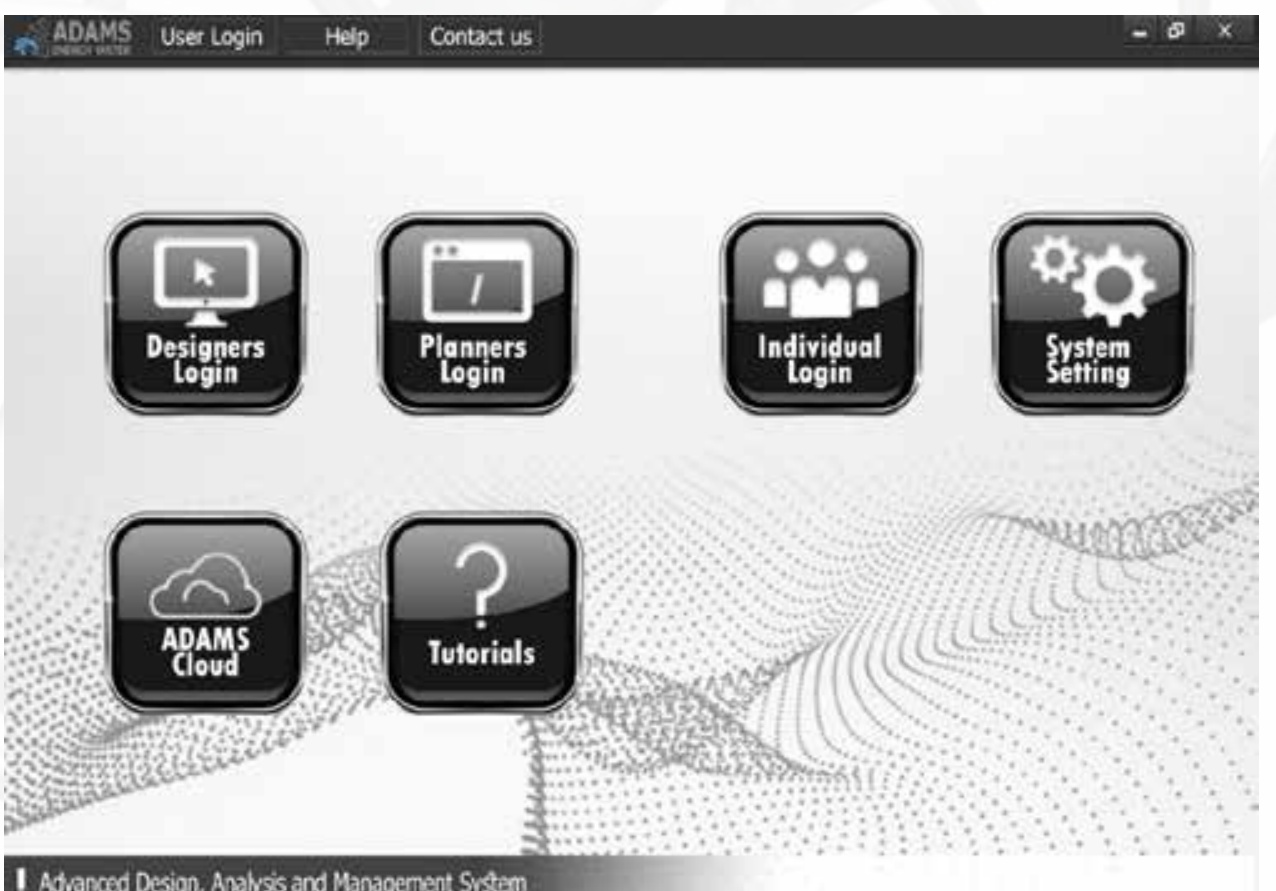

Figure 9: ADAMS main interface (Saeed \& Fadli, 2018).

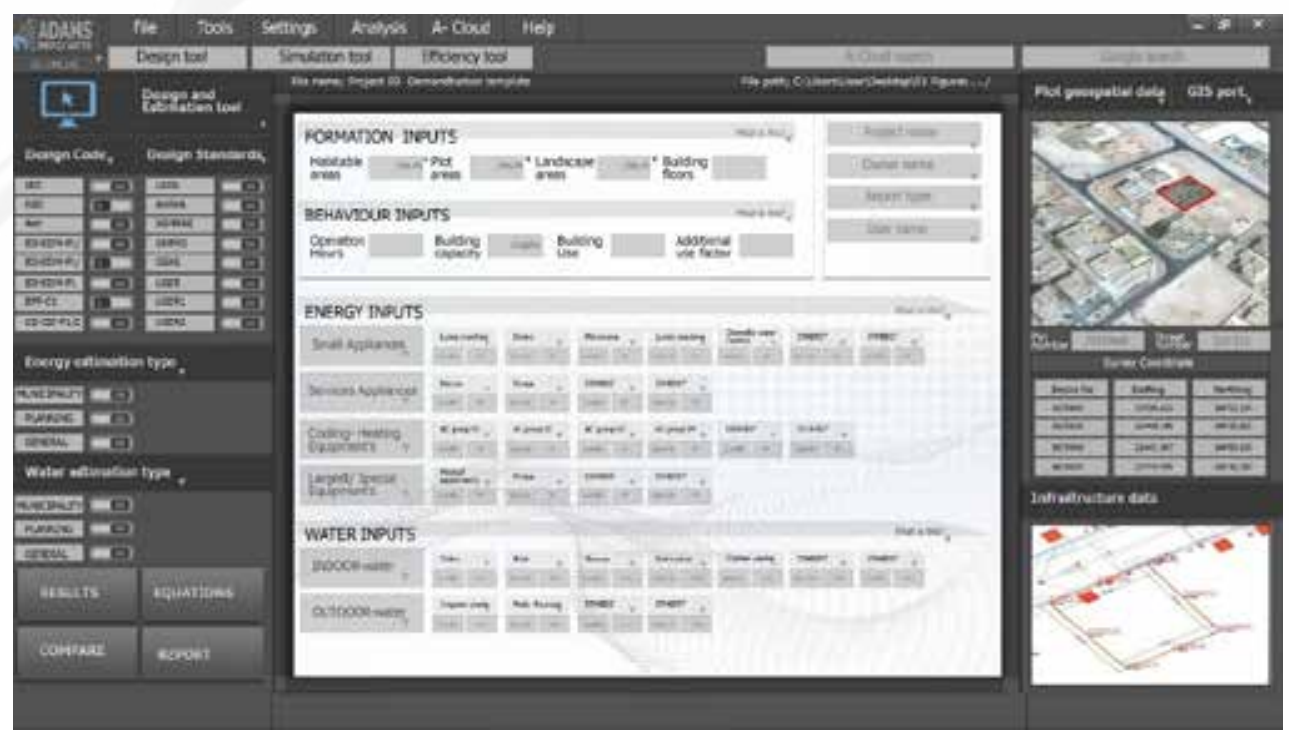

Figure 10: ADAMS design tool interface (Saeed \& Fadli, 2018).

To date, however, technology has been used primarily to organize administrative tasks and collect information rather than to manage resources and holistically formulate urban forms. Integrating the applications of computational technology with the best-practiced methods in energy and water design, planning and operation leads to reduction in the unnecessary usage of resources; increase in the estimations and consumption efficacy of energy and water, along with the creation of functional 
systematic procedures that are clear and helpful in closing the gap between users and urban structures. The created computational system obtains the essential abilities of design estimation with a high accuracy of prediction, planning principles, and operation and management methods, which leads directly to reducing the consumption of energy and water at the scale of buildings, then neighborhoods and finally the city scale.

Moreover, the system serve as real-time tracking, analysis and management platform which undoubtedly lead to reduced energy consumption and healthier livable smart interactive settlements. The findings of this study pave the way for future opportunity to develop more interactive sophisticated platforms and computerized program that work to the resolution of current and futures issues.

\section{Bibliography}

IEA, Water Energy Nexuse- World Energy Outlook. (2016). International Energy Agency: Paris, France.

Fadli, F., \& Saeed, M. (2018). Smart Cities: City Information Modeling as an Interactive Tool for Reducing Water-Energy Consumption in Urban Areas. In S.M.A.R.T. Environments: Data-driven Multivalence in the Built Environment. N. BILORIA, Editor 2018, Springer: Sydney.

Fadli, F., \& Saeed, M. (2019). Smart Cities: City Information Modelling as an Interactive Tool for Reducing WaterEnergy Consumption in Urban Areas. In S.M.A.R.T. Environments: Data-driven Multivalence in the Built Environment. B. Nimish, Editor 2019, Springer Sydney.

Boguslawski, P. et al. (2015) BIM-GIS modelling in support of emergency response applications. Building Information Modelling (BIM) in Design, Construction and Operations, 2015, 149: p. 381.

Harrison, C. et al. (2010). Foundations for smarter cities. IBM Journal of Research and Development, 54(4): p. 1-16.

Cocchia, A. (2014). Smart and digital city: A systematic literature review, in Smart city. Springer: Genoa, Italy.

Dohr, A. et al. (2010). The internet of things for ambient assisted living. In Information Technology: New Generations (ITNG), 2010 Seventh International Conference on. 2010. Ieee.

Zanella, A. et al. (2014). Internet of things for smart cities. IEEE Internet of Things journal, 1(1): p. 22-32.

Fadli, F. et al. (2015). 3D capture techniques for BIM enabled LCM. In IFIP International Conference on Product Lifecycle Management. 2015. Springer.

AlSaaed, M. (2018). Computational Technology Applications in Urban Design Processes; WE-ADAMS an Integrated Tool to Smart Energy/Water Management System. In Architecture and Urban Planing 2018. Qatar Univeristy (Suprevised by Dr. Fodil Fadli).

Eastman, C. et al. (2011). BIM handbook: A guide to building information modeling for owners, managers, designers, engineers and contractors 2011. USA \& Canada John Wiley \& Sons.

SDS (2014). Population \& land area, in Singapore, Statistics, S.D.O. Statistics, Editor 2014, Singapore e- Goverment Singapore, Lion.

Research, C.f.C. (2015). Annual Climate Assessment. Metrological Service Singapore Singapore.

Ke, W., \& Wei, K. K. (2004). Successful e-government in Singapore. Communications of the ACM, 47(6): 95-99.

Komninos, N. (2009). Intelligent cities: towards interactive and global innovation environments. International Journal of Innovation and Regional Development, 1(4): 337-355.

Keon, S. et al. (2016). International Case Studies of Smart Cities-Singapore, Republic of Singapore. Institutions for Development Sector: Singapore, Republic of Singapore. 
Leonard, S. (2014). Smart Nation Platform Industry Briefing. IDA Singapore: Singapore.

Intermediary, I.P., Internet of Things Network Management Platform, in Technology \& innovation 2014: Singapore.

P, Jothieswaran. (2015). Urban Environmental Management in Singapore P.C. Department, Editor 2015, National Environment Agency: Singapore.

Kiat, A. K. (2016). Energy Efficiency Initiatives in Singapore: Role of Government and Industries, 2016, National Environment Agency Singapore.

Cite this article as: Mahmoud A., Fadli F., "Smart Interactive Buildings [SIBs]: The use of Ambient Intelligent Systems [AMIS] to enable Smart Interactive Settlements [SISs]", International Conference on the $4^{\text {th }}$ Game Set and Match (GSM4Q-2019), Doha, Qatar, 6-7 February 2019, https://doi.org/10.29117/gsm4q.2019.0019 